\author{
C. Seignez $\cdot$ N. Adler $\cdot$ C. Thoeni $\cdot$ M. Stettler $\cdot$ \\ P. Péringer $\cdot$ C. Holliger
}

\title{
Steady-state and transient-state performance of a biotrickling filter treating chlorobenzene-containing waste gas
}

Received: 30 July 2003 / Revised: 27 November 2003 / Accepted: 28 November 2003 / Published online: 16 January 2004

(C) Springer-Verlag 2004

\begin{abstract}
Biotrickling filter (BTF) technology was applied for the treatment of waste gas containing a mixture of chlorobenzene and 1,2-dichlorobenzene. An adapted microbial community was immobilised on a structured packing material. The strategy followed was to reach high removal efficiencies at initially low mass loading rates followed by an increase of the latter. This procedure was successful and resulted in a short start-up period of only 2 weeks. A 3-month operation under steady-state conditions showed good performance, with $>95 \%$ removal efficiency at a mass loading rate of $1,800 \mathrm{~g} \mathrm{~m}^{-3}$ day $^{-1}$. Dimensionless concentration profiles showed that the chlorobenzenes were simultaneously degraded. Low dissolved organic carbon of $15 \mathrm{mg} \mathrm{l}^{-1}$ and stoichiometric chloride concentrations in the trickling liquid indicated complete mineralisation of the pollutant. Transient-state experiments with five times higher mass loading rates caused a decrease in the removal efficiency that recovered rapidly once the mass loading rate returned to its original steady-state level. A progressive increase of the mass loading rate in a long-term performance experiment showed that the removal efficiency could be kept stable between 95 and $99 \%$ at loads of up to $5,200 \mathrm{~g} \mathrm{~m}^{-3}$ day $^{-1}$ over several days. Above this mass loading rate, the elimination capacity did not increase any further. These results demonstrated that with a well-adapted inoculum and optimal operation parameters, a BTF system with excellent performance and stability that efficiently removes a mixture of cholorobenzene vapours from air can be obtained.
\end{abstract}

\footnotetext{
C. Seignez $(\bowtie) \cdot$ N. Adler $\cdot$ C. Thoeni $\cdot$ M. Stettler

P. Péringer - C. Holliger

ENAC-Laboratory for Environmental Biotechnology, Swiss

Federal Institute of Technology Lausanne (EPFL),

Bâtiment CH-B Ecublens,

1015 Lausanne, Switzerland

e-mail: chantal.seignez@epfl.ch

Tel.: +41-21-6934723

Fax: +41-21-6934722
}

\section{Introduction}

Non-biological technologies such as adsorption, absorption, condensation and incineration are normally used to remove volatile organic compounds (VOC) from waste gas. Biological technologies for waste gas treatment have up to now been applied mainly to remove odours produced during wastewater treatment and composting (Ottengraf and Disks 1990; Kennes and Thalasso 1998). However, biological technologies have also been applied for the treatment of more specific compounds in specialised systems such as biotrickling filters (BTF) well before their fundamental principles had been understood in detail (Deshusses and Hamer 1992; Deshusses 1997). A driving force to improve the performance of waste gas biotreatment systems has been the large interest of chemical industries in cost-effective treatment systems that achieve the increasingly stringent environmental regulations regarding VOC emissions.

BTFs are equipped with specially designed synthetic packing materials with a high porosity that serve as the support for the VOC-degrading biofilm. In contrast to biofilters filled with packing materials such as compost, peat, wood chips, and bark, where the packing material functions as water reservoir and source of nutrients, a liquid constantly trickling through the filter bed is necessary for wetting the biofilm, supplying nutrients such as nitrogen and phosphorous, and controlling $\mathrm{pH}$. The majority of the trickling liquid is recirculated but a certain percentage is replaced regularly depending on the compound treated. In the case of biological degradation of chlorinated compounds, the released hydrochloric acid can thus be efficiently neutralised in order to avoid a $\mathrm{pH}$ drop or too high ionic strength leading to a reduction in metabolic activity. In addition, possible non-volatile metabolic intermediates and detached or dead cells from the biofilm can also be removed. It has been shown that using the same liquid over long periods has a detrimental effect on process performance (Ottengraf 1986; Mpanias and Baltzis 1998). The BTF design of the present study was elaborated with a continuous refill and equal removal 
of liquid medium, thus avoiding the necessity for periodic total replenishment.

Chlorobenzenes, the target pollutant of this study, are known to be completely mineralised under appropriate conditions by adapted bacterial strains isolated from soil and water (Sommer and Gorisch 1997; Van der Meer 1997). Products of the degradation are carbon dioxide, water, hydrochloric acid, and biomass. A microbial community able to degrade monochlorobenzene (CB) and 1,2-dichlorobenzene (o-DCB), and cultivated with substrate pulses to high biomass concentrations with good yields has been established previously (Seignez et al. 2001). Muconic acid, an intermediate of chlorobenzene degradation, transiently accumulated during a substrate pulse. In a BTF system treating $\mathrm{CB}$ and $o$-DCB waste gas that was inoculated with this adapted microbial community, another degradation intermediate was observed in the trickling liquid that was probably chloro- or dichlorocatechol (Seignez et al. 2002).

Mixtures of chlorobenzenes such as $\mathrm{CB}$ and $o-\mathrm{DCB}$ are used as process solvent in the production of fine chemicals by our industrial partner operating a full-scale BTF for the treatment of toluene and xylene-containing waste gas (Biovent-System; Rohner, Pratteln, Switzerland). This study focuses on the steady-state and transient-state performance of a laboratory BTF treating CB- and $o$ DCB-containing waste gas. Inoculation with the adapted microbial community and careful operation during the start-up period enabled a robust treatment system with high removal efficiency to be rapidly obtained. The robustness was demonstrated with a 2-month period under steady-state conditions during which transient-state conditions were applied three times by rapidly increasing and decreasing the inflow concentration. The transient-state conditions had no effect on the steady-state performance.

\section{Materials and methods}

Biotrickling filter

Experiments were performed in a laboratory-scale downflow cocurrent BTF that has been described previously (Seignez et al. 2002), run at ambient temperature. The BTF column (40 1 total volume, $1.27 \mathrm{~m}$ height, $0.2 \mathrm{~m}$ internal diameter) was made of glass and was equipped with five ports located at $0.125,0.375,0.625$ and $0.875 \mathrm{~m}$ from the top for gas sampling. The column was filled with three cylindrical elements (height $0.3 \mathrm{~m}$, diameter $0.19 \mathrm{~m}$ ) made of structured PVC packing material (Biodek FB 10.12; Munters Euroform, Aachen, Germany) with a specific packing area of $240 \mathrm{~m}^{2} \mathrm{~m}^{-3}$, a packing density of $29.6 \mathrm{~kg} \mathrm{~m}^{-3}$, and a porosity of $96 \%$.

At the bottom of the reactor, the trickling liquid was gathered in a 0.571 vessel and automatically neutralised by addition of $\mathrm{NaOH}$ solution $(5 \mathrm{M})$ before recirculation or waste out. The mineral salt medium (Seignez et al. 2002) used to replace the trickling liquid on a regular basis contained nitrate as nitrogen source.

The empty bed residence time (EBRT) was maintained at $1.9 \mathrm{~min}$, liquid recirculation flow rate was $20 \mathrm{~h}^{-1}$ and the rate of nutrient medium addition was $0.471 \mathrm{~h}^{-1}$ at $1,800 \mathrm{~g} \mathrm{~m}^{-3}$ day ${ }^{-1}$. The waste gas was produced by injection of a mixture of pure $\mathrm{CB}$ and $o$-DCB (mass ratio $\mathrm{CB}: o-\mathrm{DCB}=4.2: 1$, corresponding to an industrial application) in the air flow by a feeding pump (Ismatec, Glattbrugg,
Switzerland) up to a maximal concentration of $8.9 \mathrm{~g} \mathrm{CB} \mathrm{m}^{-3}$ and $2.8 \mathrm{~g} \mathrm{o}^{-\mathrm{DCB} \mathrm{m}}{ }^{-3}$. A mass flow controller (5850S Brooks Smart; Brooks Instrument, Veenendaal, The Netherlands) regulated the air flux of $0.88 \mathrm{~m}^{3} \mathrm{~h}^{-1}$. The BTF was inoculated with an adapted culture (Seignez et al. 2001) of bacteria cultivated in a batch reactor with $\mathrm{CB}$ and $o$-DCB as sole source of carbon and energy.

\section{Analytical methods}

The chlorobenzene concentration of the gaseous outlet of the BTF was measured on-line with a flame ionisation detector (FID) (Kull Instruments, Oftrigen, Switzerland) in order to determine the elimination capacity and removal efficiency, and to continuously evaluate the performance of the BTF. Periodic analysis of the gas phase by gas chromatography (Shimadzu, Kyoto, Japan) equipped with a FID and a $30 \mathrm{~m}$ DB-624 capillary column (J\&W Scientific, MSP Friedli, Köniz, Switzerland) allowed determination of CB and $o$-DCB concentrations individually.

The dissolved organic carbon content of the trickling liquid was determined using a TOC analyser model TOC-5050A (Shimadzu, Kyoto, Japan). The samples were filtered through a $0.22 \mu \mathrm{m}$ filter (Schleicher \& Schuell, Riehen, Switzerland) and acidified to $\mathrm{pH} 2$ with $\mathrm{HCl}(2 \mathrm{M})$. They were purged automatically before analysis to remove carbon dioxide. In the trickling liquid, the presence of metabolites was estimated by measuring the absorbance of the filtered sample at $255 \mathrm{~nm}\left(A_{255}\right)$ in a UV spectrophotometer U-3010 (Hitachi, Tokyo, Japan). Nitrate in the liquid phase was determined by a colorimetric method (Kit $\mathrm{N}^{\circ} 14542$; WTW, Weilheim, Germany) and chloride concentrations were measured with a Chlor-o-Counter Mark II Type 400-070 (Flohr Instruments, Nieuwegein, The Netherlands). Biomass growth was evaluated by weighing the packing material elements after removal from the BTF and allowing to drip for $30 \mathrm{~min}$.

\section{Results and discussion}

\section{Packing colonisation}

Inoculation of BTFs by communities adapted to the contaminant has been shown to shorten the start-up period considerably (Veiga and Kennes 2001). A mixed bacterial community adapted to degradation of $\mathrm{CB}$ and $o-\mathrm{DCB}$ and cultivated by the substrate supply in pulses (Seignez et al. 2001) has been maintained for several years. Several biofiltration experiments were performed with slight modifications in the procedure for packing colonisation, always using the adapted bacterial community as inoculum. The procedure resulting in the shortest colonisation period is described in more detail although the other experiments had start-up periods that lasted only 12 weeks longer.

After addition of 2.51 of a suspension containing the adapted biomass at $8.6 \mathrm{~g}$ dry weight (DW) $1^{-1}$ to 2.51 of the trickling liquid, there was no liquid evacuation during the first 5 days of operation in order to enhance biofilm development on the packing material. The 51 trickling liquid was constantly recirculated at a flow rate of $431 \mathrm{~h}^{-1}$ and the chlorobenzene mass loading rate was maintained at $492 \mathrm{~g} \mathrm{~m}^{-3}$ day $^{-1}$. The only intervention during the colonisation period consisted of adding an aliquot of $100 \mathrm{ml}$ nutrient medium at days 2 and 4 to avoid bacterial 
growth limitations and to compensate for water loss due to humidification of the gas that entered dry into the BTF.

During this period, the biomass concentration in the trickling liquid decreased from 4.3 to $0.3 \mathrm{~g} \mathrm{l}^{-1}$ and the surface of the packing became progressively colonised. The chloride concentration in the trickling liquid increased, showing that the chlorobenzenes were effectively biodegraded. After 5 days of operation, the chloride concentration reached $3.2 \mathrm{~g}^{-1}$. At this time point the trickling liquid flow rate was decreased to $201 \mathrm{~h}^{-1}$ and the trickling liquid started to be replaced by fresh medium at a rate of approximately $2.5 \%$. After about 14 days, the biofilm uniformly covered the whole surface of the packing.

\section{Steady-state performance}

The evolution of total mass loading rate and the resulting removal efficiency in the course of one biofiltration experiment is depicted in Fig. 1. During the colonisation period, the mass loading rate was maintained constant at approximately $656 \mathrm{~g} \mathrm{~m}^{-3}$ day $^{-1}$ with the goal of first reaching the target maximal removal efficiency of $>90 \%$ at a given loading rate before increasing the loading rate. The removal efficiency increased rapidly to $80 \%$ during the first 5 days of operation, followed by a slow increase to $93 \%$ until day 14 . From days 15-30, the mass loading rate was increased stepwise to $1,800 \mathrm{~g} \mathrm{~m}^{-3}$ day ${ }^{-1}$ without any negative effect on removal efficiency. From day 30 on, the mass loading rate was maintained at approximately $1,800 \mathrm{~g} \mathrm{~m}^{-3}$ day $^{-1}$ for an additional period of 60 days, during which transient-state experiments were carried out. The removal efficiency not only remained constantly high but even reached maximum levels of about $99 \%$.

In an earlier study with the same laboratory BTF, removal efficiencies not higher than $65 \%$ were reached with identical mass loading rates (Seignez et al. 2002). The packing used in the previous study had a specific packing area of $125 \mathrm{~m}^{2} \mathrm{~m}^{-3}$, which is about half the area of the packing used here. Although this difference may

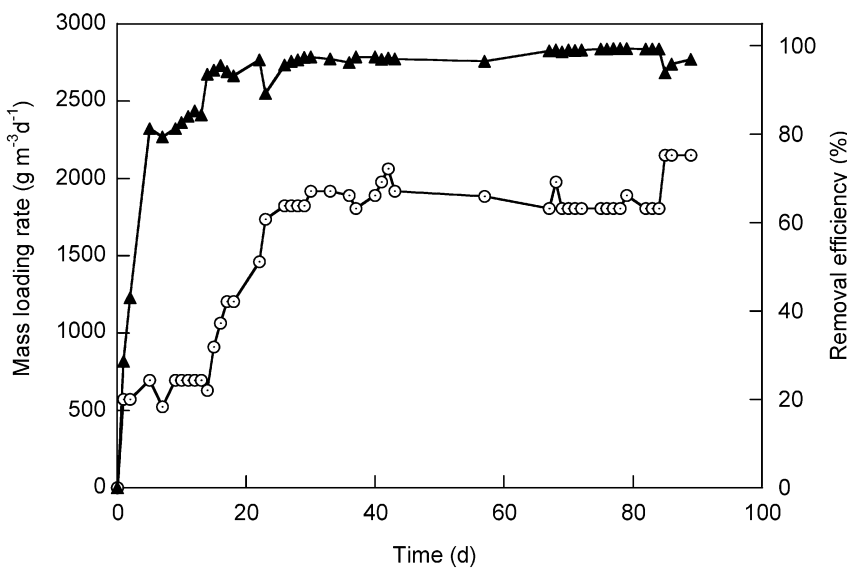

Fig. 1 Mass loading rate ( $(\circ)$ and removal efficiency $(\boldsymbol{\Delta})$ during 90 days of biotrickling operation partially explain the lower removal efficiency observed in the previous study, the lower specific packing area is probably not solely responsible for this phenomenon. In the meantime, the laboratory BTF was equipped with a different system, mixing the inlet gas and liquid flow, allowing better mass transfer in the upper part of the reactor.

The dimensionless profiles of $o$-DCB gaseous concentrations $\left(C / C_{0}\right)$ taken after $51,77,86$, and 89 days of operation clearly show the evolution of reactor performance with time (Fig. 2B). After 3 months, only about half of the BTF height was needed to completely eliminate $o$-DCB. The sharp decrease of $Z_{\mathrm{n}} / H$ between 0 and 0.2 in the upper empty part of the column containing no support (Fig. 2) was due to the relatively efficient mass transfer of $\mathrm{CB}$ and $o$-DCB from the gas to the liquid phase. Decreases of approximately $55-74 \%$ and $46-58 \%$ of the gaseous concentration were observed for $\mathrm{CB}$ and $o-\mathrm{DCB}$, respectively, corresponding to a decrease in concentration of $0.64-1.04 \mathrm{~g} \mathrm{~m}^{-3}$ for $\mathrm{CB}$ and $0.16-0.25 \mathrm{~g} \mathrm{~m}^{-3}$ for $o-\mathrm{DCB}$. The higher $\mathrm{CB}$ removal was probably due to the higher Henry constant of $\mathrm{CB}(0.141$ for $\mathrm{CB}$ and 0.063 for $o$-DCB at $25^{\circ} \mathrm{C}$ ).

The profiles in the range of $Z_{\mathrm{n}} / H 0.2-1.0$ show that the bacterial community colonising the filter bed degraded $\mathrm{CB}$ and $o$-DCB simultaneously (Fig. 2). Similar behavior has been observed for the biodegradation of two ketones in a biofilter (Deshusses et al. 1995). The gaseous concentra-
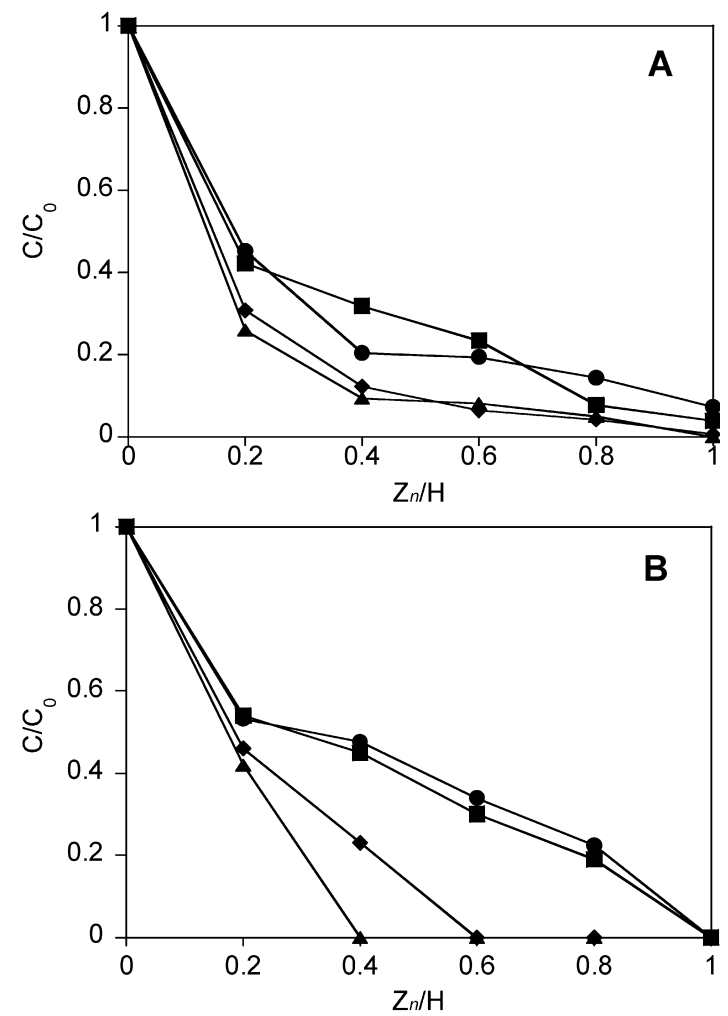

Fig. 2 Dimensionless concentration profiles of $\mathbf{A}$ monochlorobenzene $(\mathrm{CB})$ and $\mathbf{B}$ 1,2-dichlorobenzene $(o$-DCB) after $51(\bullet), 77$ $(\boldsymbol{\square}), 86(\bullet)$ and $89(\boldsymbol{\Delta})$ days of operation. $Z_{\mathrm{n}} / H$ is the ratio of height at port $\mathrm{n}$ and total height $H$ of the biotrickling filter (BTF) 
tions of $\mathrm{CB}$ and $o$-DCB decreased linearly in the filter bed, indicating a concentration-independent degradation rate. According to Ottengraf's model for the process of biofiltration in a trickling filter column (Ottengraf and van den Oever 1983; Ottengraf 1986) the performance of such a system can be modelled with the equation $C / C_{\mathrm{in}}=1$ $-\left(K_{0} H\right) /\left(C_{\mathrm{in}} v_{\mathrm{a}}\right)$, where $C\left(\mathrm{~g} \mathrm{~m}^{-3}\right)$ is the gaseous concentration, $C_{\text {in }}\left(\mathrm{g} \mathrm{m}^{-3}\right)$ is the inlet gaseous concentration, $K_{0}$ $\left(\mathrm{g} \mathrm{m}^{-3} \mathrm{~s}^{-1}\right)$ is the zero-order degradation rate constant, $H$ (m) is the height of the packed filter bed, and $v_{\mathrm{a}}\left(\mathrm{m} \mathrm{s}^{-1}\right)$ is the superficial gas flow rate (Veiga and Kennes 2001). Resolving this equation for $C$ gives the expression $K / v_{\text {a }}$ $\left(g_{C} \mathrm{~m} \mathrm{~m}^{-1}\right)$ for the slope of a regression line in a plot of the pollutant concentration along the reactor height. The zeroorder rate constant $K$ for $\mathrm{CB}$ and $o$-DCB removal was thus calculated to be $7.2 \times 10^{-3}$ and $4.3 \times 10^{-3} \mathrm{~g} \mathrm{~m}^{-3} \mathrm{~s}^{-1}$, respectively.

The biomass increase was determined as a global parameter by weighing the three packing elements before starting the experiment and twice again, after 43 and 100 days of operation. The accumulated biomass weighed 2.8 and $6.1 \mathrm{~kg}$ wet weight (WW), respectively. Establishing a carbon mass balance was not possible due to the absence of measurements of the biomass rejected by the wasted trickling liquid. However, biomass increase on the packing material is, from an applied point of view, an important parameter due to possible clogging of the filter or too large a mass increase of the whole system. The net biomass increase was $2.6 \mathrm{gWW} \mathrm{g}^{-1}$ chlorobenzenes introduced during the first 43 days of operation. A lower biomass increase of $1.6 \pm 0.3 \mathrm{gWW} \mathrm{g}^{-1}$ chlorobenzenes introduced was observed during the following 57 days under steady-state conditions, with a constant mass loading rate of $1.1 \mathrm{~kg}_{\mathrm{C}} \mathrm{m}^{-3}$ day ${ }^{-1}$. The biomass increase on the packing material caused a decrease of the porosity volume of the packing material $(25.51)$ of $24 \%$ within 100 days of operation assuming that the density of the biofilm was $1 \mathrm{~kg} \mathrm{l}^{-1}$. This indicated that there is a certain risk of pressure drop and clogging on long-term operation of the system. Interestingly, the biomass was distributed evenly on the three packing elements.

\section{Trickling liquid analysis}

The absorbance at $255 \mathrm{~nm}$, proven to be a good indicator of the removal efficiency (Seignez et al. 2002), was used to estimate the concentration of non-volatile metabolic intermediates in the trickling liquid. The absorbance at $255 \mathrm{~nm}$ remained quite constant, at around 0.6, during the 3 months of BTF operation. The average dissolved organic carbon concentration of $15 \mathrm{mg} \mathrm{l}^{-1}$ in the trickling liquid, with maximal values $<50 \mathrm{mg} \mathrm{l^{-1 }}$, indicated that no significant amounts of chlorobenzenes or soluble intermediates were removed via the wasted recirculation liquid. Regular measurements of nitrate revealed that only about $35 \%$ of the nitrogen source was consumed, demonstrating that biomass growth was not limited by the availability of this nutrient.

Degradation of $\mathrm{CB}$ and $o$-DCB acidifies the trickling liquid by releasing hydrochloric acid that was neutralised in this study by $\mathrm{NaOH}$ to maintain the $\mathrm{pH}$ at $7.0 \pm 0.2$.

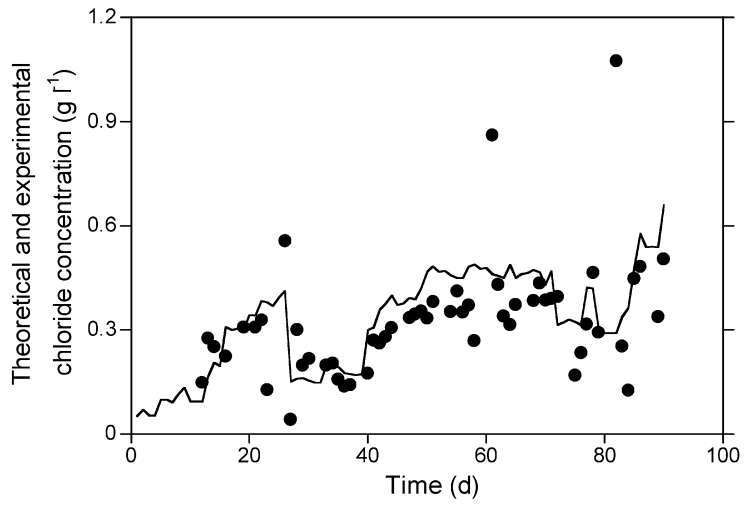

Fig. 3 The theoretical (line) and experimental (points) chloride concentrations in the trickling liquid during biofiltration

Figure 3 shows the theoretical and measured chloride concentrations over 90 days of biofiltration. Theoretical values - calculated assuming that all inflowing chlorobenzenes were completely degraded - correlated well with the experimental values. This indicated complete degradation and minimal loss of the volatile pollutants by leakages in the treatment unit. By the continuous replacement of trickling liquid with fresh medium providing nutrients, the chloride concentration was kept between 0.1 and $0.5 \mathrm{~g} \mathrm{l}^{-1}$. A chloride concentration of $7 \mathrm{~g} \mathrm{l}^{-1}$ has been shown to cause inhibition of bacterial metabolism in a BTF treating chlorobenzene-contaminated air (Oh and Bartha 1994).

\section{Transient-state performance}

Long-term performance of laboratory systems is often tested at a constant mass loading rate. Here, the mass loading rate was maintained at about $1,800 \mathrm{~g} \mathrm{~m}^{-3}$ day $^{-1}$ $\left(1.83 \mathrm{~g}_{\mathrm{CB}} \mathrm{m}^{-3}\right.$ and $\left.0.58 \mathrm{~g}_{\mathrm{DCB}} \mathrm{m}^{-3}\right)$, which resulted in constant elimination capacity and a removal efficiency of 95-99\%. However, constant loading rates are not typical of industrial applications. Transient-state experiments were carried out on days 34, 40, and 53. The transientstate conditions consisted of a gradual but rapid increase of the mass loading rate, reaching a five times higher loading rate within $2-3 \mathrm{~h}$ followed by a decrease to the original mass loading rate within $2-3 \mathrm{~h}$. Changes in mass loading rate were achieved by increasing the gaseous inflow concentration only; EBRT was kept constant.

The elimination capacity increased simultaneously with the mass loading rate although, above $4,900 \mathrm{~g} \mathrm{~m}^{-3}$ day $^{-1}$ $\left(5.0 \mathrm{~g}_{\mathrm{CB}} \mathrm{m}^{-3}\right.$ and $\left.1.6 \mathrm{~g}_{\mathrm{DCB}} \mathrm{m}^{-3}\right)$, at a slower rate (Fig. 4). This resulted in a gradual decrease of the removal efficiency to a minimum of $55 \%$. The removal efficiency increased after the loading rate reached its minimum value and recovered the original high values of $>95 \%$ a few hours after the shock load. The $A_{255} \mathrm{~nm}$ increased rapidly up to 1.3 due to accumulation of degradation intermediates but also returned to original levels shortly after the shock load. This indicated that a later step in the degradation of the chlorobenzenes was the rate-limiting reaction and that biodegradation and not mass transfer was limiting the elimination capacity. Toluene degradation in a BTF was also limited by biodegradation, and was independent of gas-liquid mass transfer (Pedersen and Arvin 1995). 


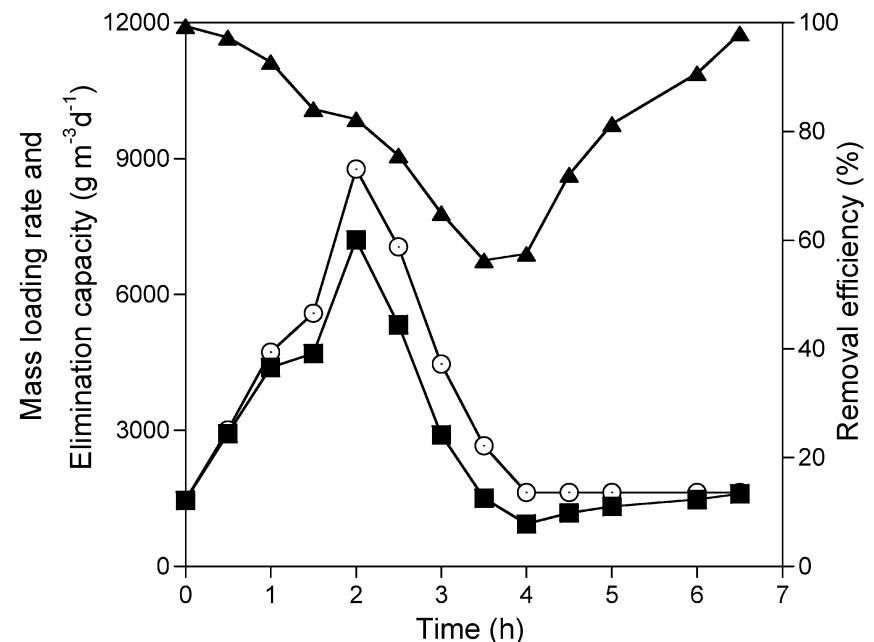

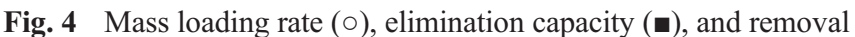
efficiency $(\mathbf{\Delta})$ during a transient-state experiment

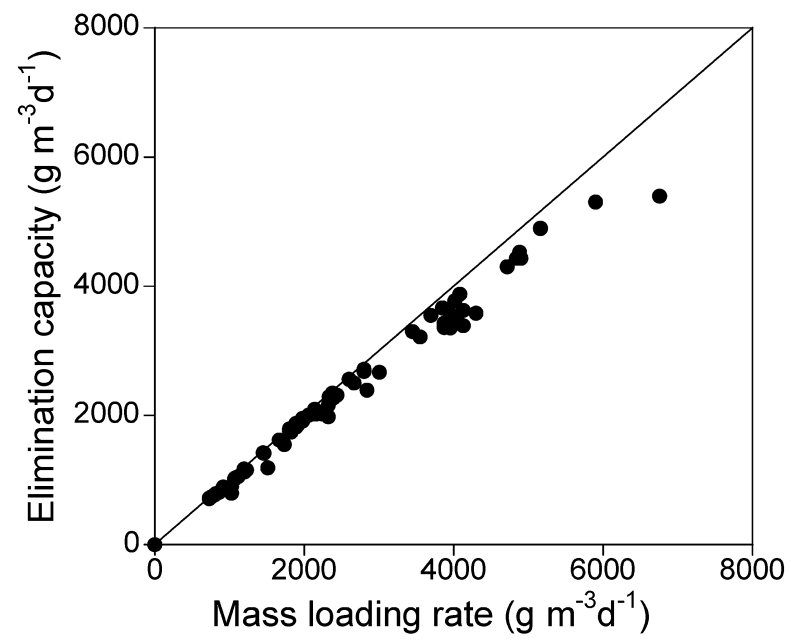

Fig. 5 Mass loading rate versus elimination capacity. - Experimental values, straight line theoretical $100 \%$ elimination capacity

Similar phenomena during transient-state conditions have been observed for a BTF treating acetone or propionaldehyde (Kirchner et al. 1996). For the latter compound a 10-fold increase in the gaseous inflow concentration caused a decrease in the removal efficiency of $30 \%$. An intermediate accumulated that was rapidly consumed after reducing the mass loading rate, and the system again showed the same high performance as before the shock load. With acetone, a decrease in removal efficiency of $40 \%$ was found and the reactor did not recover from the shock load.

The transient-state experiments showed the high stability and limits of the chlorobenzene-treating BTF system. A further step towards the operation conditions of a full-scale industrial BTF would be to evaluate performance at constantly fluctuating mass loading rates including periods of starvation.

\section{Maximal elimination capacity}

In another 3-month BTF performance experiment, the mass loading rate was not kept constant after the start-up period but continuously increased from 660 to $6,900 \mathrm{~g} \mathrm{~m}$ ${ }^{-3}$ day $^{-1}$ between days 40 and 90 with simultaneous increase of the nutrient medium rate to $1.0 \mathrm{l} \mathrm{h}^{-1}$ to avoid nutrient limitation. Figure 5 shows the resulting elimination capacity in relation to the mass loading rates. Although the BTF could not be operated for a long period at high mass loading rates due to technical limitations, this experiment showed that above a mass loading rate of $4,900 \mathrm{~g} \mathrm{~m}^{-3}$ day $^{-1}$ the elimination capacity started to level off. Up to a mass loading rate of $5,200 \mathrm{~g} \mathrm{~m}^{-3}$ day $^{-1}$ the removal efficiency was at least $95 \%$. The maximal elimination capacity attained was $5,100 \mathrm{~g} \mathrm{~m}^{-3}$ day $^{-1}$ at an inlet chlorobenzene concentration of $6.7 \mathrm{~g} \mathrm{~m}^{-3}$. Measurements of dissolved oxygen and nitrate in the trickling liquid showed that these two parameters were not limiting biodegradation. However, the performance of the BTF system studied here surpassed a previously presented BTF treating chlorobenzene vapours with a maximal elimination capacity of $1,350 \mathrm{~g} \mathrm{~m}^{-3}$ day $^{-1}$ at an EBRT of $3.8 \mathrm{~min}$ and an inlet concentration of $4.4 \mathrm{~g} \mathrm{~m}^{-3}$ (Mpanias and Baltzis 1998).

\section{References}

Deshusses MA (1997) Biological waste air treatment in biofilters. Curr Opin Biotechnol 8:335-339

Deshusses MA, Hamer G (1992) Methyl isobutyl and methyl ethyl ketone biodegradation in biofilters. In: Tramper J (ed) Biocatalysis in non-conventional media. Proceedings of an International Symposium. Elsevier, Amsterdam, pp 393-399

Deshusses MA, Hamer G, Dunn IJ (1995) Behavior of biofilters for waste air biotreatment. 1. Dynamic model development. Environ Sci Technol 29:1048-1058

Kennes C, Thalasso F (1998) Waste-gas biotreatment technology. J Chem Technol Biotechnol 72:303-319

Kirchner K, Wagner S, Rehm HJ (1996) Removal of organic air pollutants from exhaust gases in the trickle bed bioreactor. Effect of oxygen. Appl Microbiol Biotechnol 45:415-419

Mpanias CJ, Baltzis BC (1998) An experimental and modeling study on the removal of mono-chlorobenzene vapor in biotrickling filters. Biotechnol Bioeng 59:328-343

Oh Y-S, Bartha R (1994) Design and performance of a trickling air biofilter for chlorobenzene and $o$-dichlorobenzene vapors. Appl Environ Microbiol 60:2717-2722

Ottengraf SP (1986) Exhaust gas purification. In: Reed G (ed) Biotechnology: a comprehensive treatise, H-J Rehm edn. Verlag Chemie, pp 426-452

Ottengraf SP, Disks R (1990) Biological purification of waste-gases. Chim Oggi 8:41-45

Ottengraf SPP, van den Oever AHC (1983) Kinetics of organic compound removal from waste gases with a biological filter. Biotechnol Bioeng 25:3089-3102

Pedersen AR, Arvin E (1995) Removal of toluene in waste-gases using a biological trickling filter. Biodegradation 6:109-118

Seignez C, Vuillemin A, Adler N, Peringer P (2001) A procedure for production of adapted bacteria to degrade chlorinated aromatics. J Hazard Mater 84:265-277

Seignez C, Atti A, Adler NPP (2002) Effect of biotrickling filter operating parameters on chlorobenzenes degradation. J Environ Eng 128:360-366

Sommer C, Gorisch H (1997) Enzymology of the degradation of (di) chlorobenzenes by Xanthobacter flavus $14 \mathrm{p} 1$. Arch Microbiol 167:384-391

Van der Meer JR (1997) Evolution of novel metabolic pathways for the degradation of chloroaromatic compounds. Antonie Van Leeuwenhoek 71:159-178

Veiga MC, Kennes C (2001) Parameters affecting performance and modeling of biofilters treating alkylbenzene-polluted air. Appl Microbiol Biotechnol 55:254-268 